\title{
Mission, Money, and Merit: Strategic Decision Making by Nonprofit Managers
}

\author{
Kersti Krug \& Charles B. Weinberg \\ Faculty of Commerce and Business Administration (now Sauder School of Business) \\ The University of British Columbia \\ 2053 Main Mall, Vancouver, Canada V6T 1 Z2 \\ Tel: Krug 604-822-2932, Weinberg 604-822-8327 \\ E-mail: kersti.krug@ubc.ca; chuck.weinberg@commerce.ubc.ca
}

\begin{abstract}
:
Public and nonprofit organizations need to make strategic choices about where to invest their resources. They also need to expose hidden managerial assumptions and lack of adequate knowledge that prevent the attainment of consensus in strategic decision-making. The approach we developed and tested in the field used a dynamic, three-dimensional model that tracks individual programs in an organization's portfolio on their contribution to mission, money, and merit. The first dimension measures whether the organization is doing the right things; the second, whether it is doing things right financially; and the third, whether it doing things right in terms of quality. Senior managers provide their own evaluations of the organization's programs. Both the consensus view and the variation in individual assessments contribute to an improved managerial understanding of the organization's current situation and to richer discussions in strategic decision-making. In field tests, this visual model proved to be a useful and powerful tool for illuminating underlying assumptions and variations in knowledge among managers facing the complex, multidimensional trade-offs needed in strategic decision-making.
\end{abstract}

This article is published in Nonprofit Management \& Leadership, Vol. 14, No. 3, Spring 2004, pp. 325-342. Nonprofit Management \& Leadership is sponsored by the Mandel Center for Noprofit Organizations, Case Western Reserve University, Cleveland, Ohio, and published by Jossey-Bass, San Francisco, California.

The research was supported by the Hampton Research Fund of the University of British Columbia. 


\section{Introduction}

The challenge for nonprofits is to ensure that revenues can be sustained while focussing on essential purposes. Basic questions that leaders of nonprofit organizations must answer include: How does each program within our complex portfolio of programs advance our mission? How much does each cost and how much revenue does it contribute?

To help answer these central questions, we began with a two-dimensional portfolio model that could illuminate for managers how their programs advance mission and contribute to revenues (Lovelock \& Weinberg, 1980; Krug, 1992). Our model would continue the work of scholars who have been developing strategic effectiveness tools for nonprofit organizations. Approaches such as the Balanced Scorecard (Kaplan \& Norton, 1996; Kaplan, 2001) go well beyond mere financial or ad hoc measures that limit the effectiveness of nonprofit decision-making to better frame the multidimensional nature of such decisions on mission and strategy. These tools provide useful mechanisms for nonprofit managers to respond not only to increasing competition for donor and government funding, but also to growing demands for transparency and public accountability.

As our portfolio model had not been tested in actual organizations, we prepared it for the field. But the two-dimensional model, limited by the visual technology of the time, failed to incorporate an important third dimension. Not only should nonprofits be able to assess mission and financial contributions of any program, they should be able to assess its merit. The model should be able to answer the question: How well do we perform this program?

By taking advantage of the capacity of current computer technologies, we were able to add our third dimension to the other two, as well as gather input and demonstrate for users what was happening. What we took into the field, then, was a dynamic, interactive, three-dimensional model that would add to the existing body of work by combining visually and dynamically what we believed were the three essential elements in strategic decision-making: mission, money, and merit.

But soon after entering our first organization, we discovered that the model did something more. It exposed underlying assumptions and varying levels of knowledge that program managers were bringing to strategic discussions. The model could apparently help leaders of nonprofit organizations get answers to another critical question: How do the assumptions and knowledge levels of my managers influence the effectiveness of our organization-wide decision-making?

\section{The Model}

The model is illustrated in Figure 1. Its three measures track the contribution of individual programs in an organization's portfolio of programs against mission, money, and merit - illustrated here for a museum. Employing the useful expressions given to us by Peter Drucker, the first dimension measures whether the organization is 'doing the right things'; the second, whether it is 'doing things right' financially; and the third, whether it is 'doing things right' in terms of quality. It can be problematic to support a program that covers its own costs but thwarts mission, just as it can to support one that advances mission and covers its own costs but performs ineffectually. 
Figure 1:

3-DIMENSIONAL PORTFOLIO

of 10 programs in a Iypothetical musetm

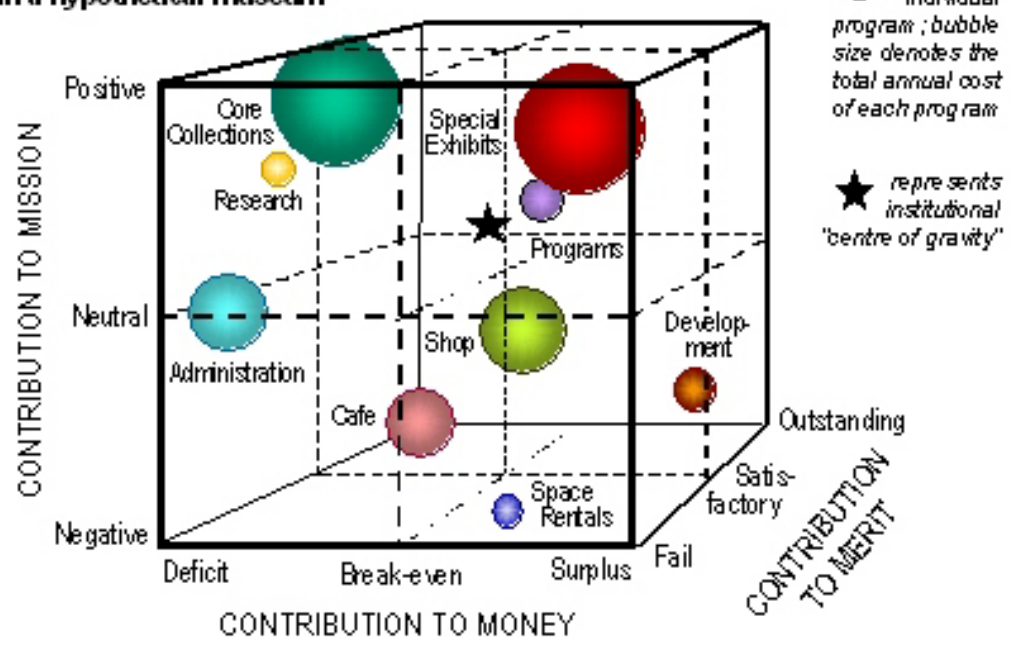

Bubble sizes represent the associated cost of each program, allowing the organization to quickly see relative 'price tags' or annual financial investments in individual programs. Bubble locations allow it to see how well each program stacks up against the advancement of mission, covers its own costs, and is performed. By visualizing the quadrant in which different programs are positioned, managers can more readily isolate which should be bolstered, cut, or restructured. By weighting each program by its bubble size or cost, the overall average of program dimensions can be computed, enabling the nonprofit to mark its 'centre of gravity' - the star-shaped pointer that permits it to see where the organization as a whole stands relative to these dimensions. Over time, management can measure progress as it moves programs in positive directions on mission, money, and merit axes, or changes the relative size of program bubbles.

Using a visually engaging, broadly interactive, and common computer program (in this case, Microsoft Excel), we were able to work with managers in several nonprofit organizations to test and further develop our system. The initial empirical work was undertaken in North American museums, in part because the political, economic, and socio-cultural environments for museums have changed significantly over the past twenty years. With decreasing government support, museums entered a new world in which some forgot what their missions were or actively abandoned them because traditional mission activities appeared unhelpful in their search for new funding sources. For many, it became a world where budget deficits created cycles of cuts, layoffs, and sometimes complete elimination of core programs. It resulted in great turmoil but also substantial rethinking of organizational purposes. Within this dynamic environment, the model could be tested to show its weaknesses, strengths, and areas for expansion or improvement.

What we will discuss here is what we learned from our interactions with directors and managers of eight American and Canadian museums, art galleries, and aquariums, as well as with program evaluators and other museum professionals. To more easily illustrate how the model worked for the nonprofits we visited and how it could aid management in other nonprofit organizations, we have aggregated and simplified our findings from the field. 


\section{Model Elements}

The model has four principal elements:

- the Program and its Cost,

- Mission,

- Money (or revenue / cost coverage), and

- Merit (or performance quality).

The Prog ram is the system's basic building block. The definition of what constitutes a program and what is included or excluded was unique to each organization studied, and reflected historic accounting, governing, or structural breakdowns.

Once each program was defined, the model required its total annual cost, preferably including all direct and indirect costs, whether internally or externally directed. Prog ram Cost is an estimate of the organization's overall investment in a program. In the portfolio diagram, cost defines the size of program bubbles to give management a quick visual overview of where its resources are deployed and where intervention might have greatest financial or operational impact.

Mission Contribution is a qualitative judgment guided by existing mission statements and institutional mandates. Input was sought from single individuals then rolled up as an average assessment by all participants. The average could reflect a genuine consensus but could also be a trade-off among widely divergent opinions about mission. These were made explicit by the model which illuminated assumptions governing managers' judgments. In the process of exploring how and why managers arrived at their assessments, leaders got an opportunity to test organizational missions as well as discover contradictory interpretations of mission statements. It thus became possible to correct misdirected actions arising from inaccurate assumptions.

A Tale from the Field: The mission statement of a large regional museum spoke of service to the people of the region, including its founding peoples. Despite the existence of a recently revised mission statement, senior managers differed significantly in their interpretation of how or whether their Special Exhibitions advanced mission. One manager concluded this: 'Last year, when we presented 'Exhibition X' [the inventions of a long-dead European], mission was not advanced because this inventor has nothing to do with our region. But this summer, when we produced 'Exhibition $Y$ ' [an exhibit organized with a nearby community of originating people], our mission was perfectly advanced." A second manager concluded the opposite: "This year mission was not well advanced because not many visitors came to see our community-based exhibit - apparently it was only marginally relevant to the public we claim to serve. But last year, when we got huge crowds from all across this region to see the inventor's show, mission was better advanced because that exhibit reached and was relevant to our public."

Contribution to Money requires both expense and revenue data. These quantitative measures are usually taken from financial tables. However, cost accounting includes not only real numbers but also underlying qualitative judgments and accounting precedents for how fundraising, common services, administrative overheads, or general revenues are allocated to specific programs. Deciding which cost and revenues are best represented where created dilemmas when applying the model. However what the model could do was focus attention on relationships between parts, expose how accounting procedures were making difficult the realistic allocation of overheads among different programs, and isolate systemic ills that jeopardized equitable recognition and reward tied to real performance and real contribution. 
A Tale from the Field: In a medium-sized museum, evidence of dissent among program managers was attributed in part to how costs and revenues were apportioned to programs. On the revenue side, donations were counted entirely within Development, making this small unit appear exceptionally successful. Programs like Exhibitions and Collections, which had attracted the gifts, did not see their contribution to fundraising lined up against their high costs. On the cost side, some expenses incurred by Public Programs, Space Rentals, and Development were not counted in those programs but in Collections and Curatorial Research which provided the services. When Programs needed a curator to make a presentation or when a fundraising or rental event needed collections staff to create the 'right' museum ambiance, those costs were not passed on to Programs, Rentals, or Development. As a result, these three programs were considered 'lean' while Collections and Curatorial Research were 'fat' - albeit 'necessary museum burdens.' Myths about lean and fat programs were hurting managerial teamwork, and risking the museum's capacity to make intelligent adjustments based as they were on historically skewed or emotionally loaded information.

The process of cost allocation and revenue attribution is an important one. These tasks would be made easier and there would be more consensus if nonprofits adopted management control procedures such as those advocated in Anthony \& Young (1984). In practice, organizations vary considerably in their use of control systems, perhaps judging that the cost and time involved are too great for any benefits obtained. One outcome of our model testing, then, was to show the value of more accurate measurement.

Contribution to Me rit reflects how well a program performs. It combines qualitative and quantitative measures depending on what criteria are relevant, what standards are applied, and what research instruments are used. In the museums we studied, attendance is a quantitative measure; what visitors experience is a qualitative one. Although there are many effective evaluation programs (Chelimsky \& Shadish, 1997), resistance to outcome or performance measurement is not uncommon in museums and other nonprofit organizations. Evaluation may be seen to restrict professional freedom or challenge expert judgment - especially when providers of services are so well intentioned. These attitudes do much to alienate program evaluators, visitor researchers, and comprehensive auditors whose research and advice are often ignored. But by allowing the structured illumination, analysis, and discussion evoked by the model as lead-ins to awareness and agreement, we discovered that different professions could come together in a common cause to improve organizational effectiveness and better respond to public calls for accountability.

A Tale from the Field: In one museum, some senior staff suggested that only peers could judge the merit of their work. "But as there are so few experts who actually know what standards to apply, judgments about quality are best left to insiders properly trained to assess it." Others suggested that if their organization's mission was to educate the public, it made little sense to allow the masses to comment on what was delivered. "It's like getting students to evaluate a professor's work. They don't know enough." In another museum where program evaluation was an ongoing and well accepted function, managers across the organization contributed significant, and sophisticated, input to this third axis.

To summarize, all three axes of the model suffer from the same issues as those described in contribution to money. Contributions to mission and merit should also be measured systematically, but organizations often choose to invest resources in areas other than measurement.

\section{Building the Model}

The model is built by converting all elements, both quantitative and qualitative, to numbers. This includes creating and positioning program bubbles. Our illustration in Figure 2 assumes a hypothetical museum with three programs - Special Exhibitions, Core Collections, and Space Rentals. The first, Special Exhibitions, has high curatorial, research, design, construction, public security, publication, insurance, advertising, and other costs adding to $\$ 10$ million. Its bubble would 


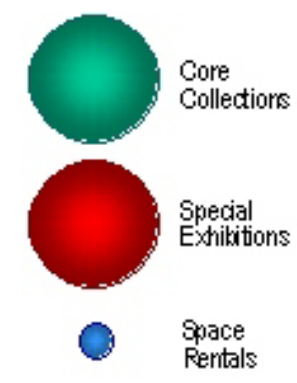

Figure 2:

RELATIVE BUBBLE SIZES

of 3 sample museum programs be big. The second, Core Collections, has collections registration, storage, loans, data base management, conservation, and building security costs adding also to $\$ 10$ million. This program is equally big. Space Rentals has marketing, coordinating, event staffing, special security, and cleaning costs, adding to $\$ 1$ million. Its bubble area is $1 / 10$ th the size of the other two.

It is important that programs not include so much that people cannot get their minds around what each contains, nor so little that the whole organization is represented by a mass of meaningless activities. Six to ten programs on one graph are ideal. To avoid problems inherent in comparing very large programs with very small ones, programs included in one graph should vary in size by no more than a factor of ten. A balance must be struck between capturing organization detail that is meaningful to middle managers yet provides a broad overview to leaders or board members. Both can be achieved by rolling activities up from the small to the large through graphic layers.

\section{Inputting to the Model}

Once programs are defined by the organization, they can be positioned on the graph. To construct comparative analyses, position values also must be converted to numbers. In our research, organizational participants put their personal assessments directly in the Excel spreadsheet which then translated their individual and collective input to dynamic visuals.

Numbers allocated to the three axes must have intuitive meaning for managers. As we found to work in our research and show in Figure 3, the Mission Axis uses zero for a neutral contribution to mission (neither advancing nor detracting), +5 for a maximum positive contribution, and -5 for maximum negative contribution. Anything with a minus sign is not neutral but detracts from mission. The goal is to have all programs above or on the centre line.
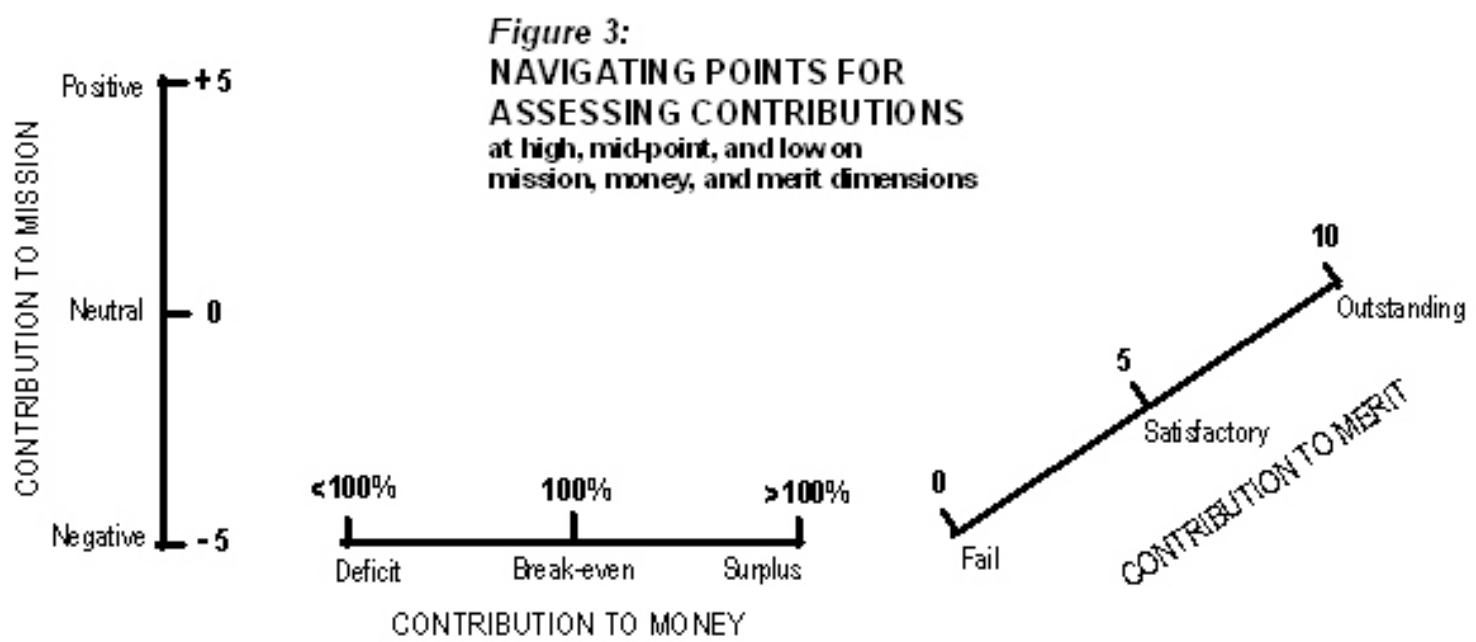
On the Money Axis, programs that covered one hundred per cent of their own costs with attracted revenues were positioned at the break-even point. Programs that were net cost centres were placed within the negative part of the axis. Programs that more than covered their own costs fit between the break-even line and positive extreme of the axis depending on the size of their surplus. These surpluses subsidize other programs. The goal of nonprofits is typically not to seek surpluses from every program, but to achieve a balanced budget from the total program mix - an ofttimes more difficult goal than 'simply' aiming to maximize profits. Nonetheless, museums and many other nonprofits are able to mobilize fundraising efforts that can cover differences - a necessary capacity for ensuring adequate surpluses to build short- and long-term financial strength.

The Me rit Axis uses the familiar grading structure of outstanding, satisfactory, and fail, with the maximum score 10 , the mid-point 5 , and the minimum 0 .

\section{Rating the Programs}

Within the spreadsheet, input was gathered at three levels: first, what participants perceived to be the 'actual' (that is, their best estimate of actual); and second and third, what they believed were upper and lower extremes of that 'actual' - the range within which reasonable judgment would fall. One manager in our field tests worked it out this way: "I think the actual or overall contribution to mission for our Special Exhibitions is +3 , but a few of our exhibits actually detract from mission so those slip to -1 , while others perfectly advance mission putting them at the top." This manager's input therefore was +3 for 'actual' flanked by a range of -1 to +5 . The money and merit axes elicited similar examples. By providing a range within which managers could fit their assessments, the model offered some comfort to those hesitant to state only one figure which they feared would be 'wrong.'

Because each manager's input was provided individually and anonymously, when we displayed the estimates on projection screens and clicked on averages, lows, and highs, we saw dynamic dances of program bubbles. To our delight, these elicited humour, rich discussions, and critical reflection. For example, a program bubble that flew wildly from one extreme to the other suggested that there was significant diversity of opinion, knowledge, or standards among managers. When a program bubble moved little or not at all, it was taken as a sign of wide consensus, shared managerial understanding, or, as someone suggested, the troublesome sign of uncritical group-think. Either way, and to paraphrase one of our reviewers, the picture was worth a thousand words.

\section{Interpreting the Model}

Once programs are defined and costed and a way of positioning them on the axes has been agreed to, programs can be placed on the multiple dimensions of the model and viewed as colourful, dynamic visuals. For illustration, only the three sample programs of a hypothetical museum (Exhibitions at $\$ 10 \mathrm{M}$, Collections at $\$ 10 \mathrm{M}$, and Space Rentals at $\$ 1 \mathrm{M}$ ) are shown. This simplified example from our research assumes that ten senior managers have participated in assessing how the three programs contribute to mission, money, and merit.

Contribution to Mission: Figure 4 shows that the average of these ten managers' assessment of mission advancement places Core Collections at +4 , Special Exhibitions at +3 , and Space Rentals clearly detracting from mission at -4 . In our field work, judgments regarding mission 
drew on whatever written mission statement existed, or if there was none, on whatever managers believed was the working mission.

Effective mission statements are a critical part of building the model. Peter E. Drucker (1989) argues that they are also critical in building nonprofit organizational health. The importance of mission, he argues, is to "focus the organization on action ... It defines the specific strategies needed to attain the crucial goals. It creates a disciplined organization. It alone can prevent the most common degenerative disease of organizations, especially large ones: splintering their always limited resources on things that are 'interesting' or look 'profitable' rather than concentrating them on a very small number of productive efforts ..." (Drucker, 1989, pp. 89-90).

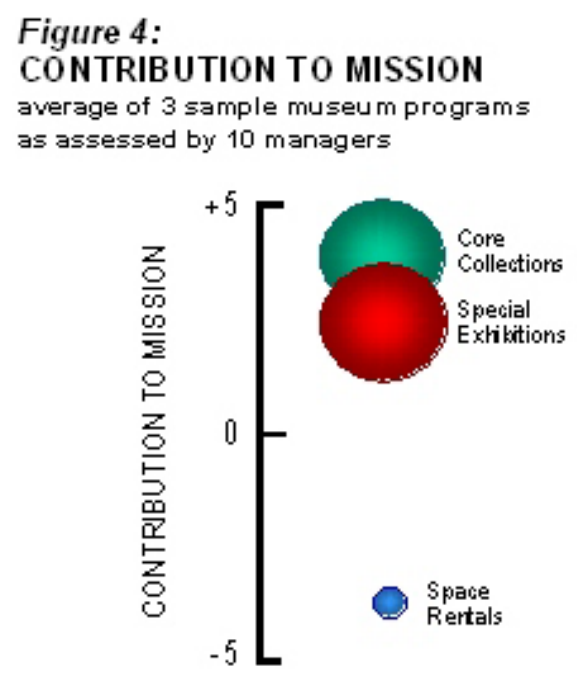

We concluded from our research that the model could contribute not so much to the writing of a mission statement as to its refinement. By working through the model, each organization approached its statement in a sense backwards, starting not from blank paper, but from its ultimate impact assessed here by the program managers who were producing the results. Because the model unveiled many underlying assumptions that were colouring interpretations of what was written in a mission statement, it exposed what was fuzzy or too open to interpretation - or simply not working as intended. Occasionally, the model unearthed multiple versions of 'current' mission statements.

Once all input was collected and entered, the museum could see how various programs contributed to its overall mission - thus answering the question: Are we doing the right things? With apparent consensus that Core Collections and Special Exhibitions are contributing positively to mission, management might now focus on moving Space Rentals up the mission axis. For example, the museum could decide to stop renting museum spaces to corporations that only seek convenient locations, and rent instead to sponsored community services, educational events, or companies that find value in their particular space.

To test the presence or absence of consensus in our field tests, we displayed to the collective management group each manager's anonymous judgment regarding program contributions to mission. The evidence that there existed differences in perception invariably evoked active group discussion during which new insights emerged. As we saw in one museum, some managers assumed that the relevance of Special Exhibitions was tested through exhibit content, whereas others assumed that the test was its relevance to the museum's visiting public. The visual display of these different perceptions came more as an interesting fact than as disagreements to be attacked or defended. In fact, some managers self-revealed even though they did not need to. It led to discussions about how they could move toward a more genuine consensual support, especially for difficult decisions. Individuals sitting around the table were coming to understand why decisionmaking in the past had evoked unpleasant dissent, or why, in reaction to the unpleasantness, the quality of decisions had settled for what someone called the lowest common denominator. 
Contribution to Money: The goal itself - to survive, or to minimize deficits rather than maximize income - can be seen as a fundamental difference between nonprofit financial management and that of for-profits. Ichak Adizes argues that this built-in budgeting bias creates special difficulties for nonprofits in that "deficit budgeting may increase deficits rather than reduce them. Usually the organization tends to underestimate expenses and overestimate income. If it did not show a small planned deficit, it would encounter difficulties in raising funds to cover the gap. In reality the expenses are higher and the income is lower. . . and the organization is deeper in debt than before" (Adizes, 1972, p. 101).

A way of balancing the budget that does not emphasize limiting deficits requires that the nonprofit organization visualize more clearly how each program offers both opportunities for revenue maximization while still finding ways to support core programs with fundraising. Figure 5 shows the results of the same ten managers' assessments about where each program lies relative to the revenues raised to cover its own total annual cost. If these three programs were all that the museum delivered, the institution would be in deficit, perhaps rapidly going broke. Although Special Exhibitions covers its own costs and Space Rentals provides subsidies to other programs, the large cost of Core Collections which draws in few revenues pushes the balance below break-even. The organization is getting answers to its question: Are we doing the right things financially?

The model visuals can more effectively focus management on specific programs when considering potential actions: e.g., pushing Rentals to be more profitable, reducing the overall cost of Collections through economies and efficiencies; tightening up project management of Exhibitions and seeking more sponsorships, grants, or gate revenues; or concentrating fundraising efforts in more innovative ways. When it becomes this obvious that Collections, the traditional core of a museum's existence, is endangered by the burden its care places on the rest of the institution, senior managers and fundraising officers might refocus efforts from traditional, non-specific, or subsidizing efforts to creative approaches that directly link Collections needs to fundraising strategies. The constraint can become an impetus to innovative fundraising ideas.

In our field tests, the money axis called for costs and revenues to be 'corrected' after the exercise by the financial officer. Both averages and extremes of opinion were checked as well. In the process of checking, managers exposed both their assumptions and their level of knowledge. Some expressed significant distress at not knowing the real costs and contributions of different programs, occasionally even their own. Several acknowledged that they had not really appreciated, for example, the high cost of Collections, nor did they know that Space Rentals was not bringing in enough income to subsidize it. Several added that they should know these things. Some recognized that they had been focussing on financial survival rather than financial balance.

Contribution to Me rit: Indicators of program merit or quality are analyzed through the third axis of the model. Although some may argue that organizational performance is adequately considered on the money axis, this would limit managerial information to economy and efficiency, 


\section{Figure 6:}

\section{CONTRIBUTION TO MERT average of 3 sample museum programs as assessed by 10 managers}

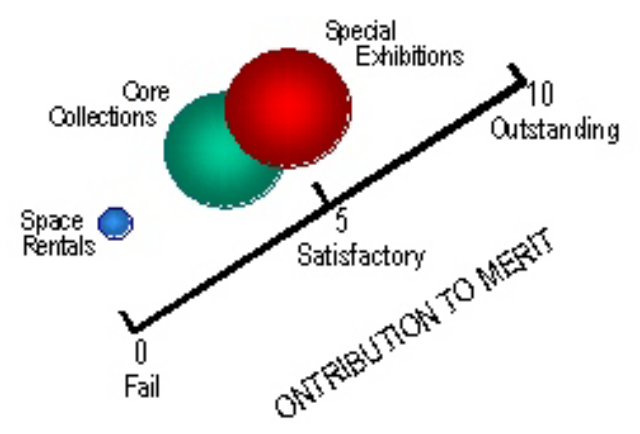

not merit or quality. Focussing on economy or efficiency, says Peter M. Jackson, has these negative outcomes: "Whether or not you are in the public sector [or] the private sector the fundamental objective of management is to create or add value .... Value for money performance indicators tend to focus narrowly upon economy and efficiency. That is, upon cost-cutting through reducing inputs. An immediate casualty of this approach is quality. To remain within declining budgets while service demands are increasing implies that quality is cut back. Many 'apparent' efficiency gains ... amount to nothing more than an erosion in the quality of services (Jackson, 1995, p. 3).

The performance axis is illustrated in Figure 6. The average of ten managers shows a rather lackluster museum. Space Rentals are an embarrassment (event organizers cover up the museum's impressionist art works with their own velvet paintings); collections are deteriorating (artifacts are dusty, thefts have occurred, and top conservators have left for institutions with higher standards). Neither program bolsters the uneven productions of Special Exhibitions (good ones are interspersed with shoddy ones, not only confusing visitors but over time undermining word-of-mouth promotion on which museums rely). Although Exhibitions and Collections contribute positively overall to mission, and although Exhibitions and Rentals are economically sound, the quality of their delivery is a different matter. Mission and money are not enough.

After seeing results on the third dimension, the nonprofit can answer: Are we doing things right in terms of quality? It can better see where to put its efforts to improve program performance, raise standards, and possibly discontinue or replace programs that it does very poorly, knows it can never improve, and are best left for others. In our field tests, the personal tastes and critical standards of managers were exposed as the model made visible the diversity of judgments. Again, these launched constructive discussions that promised to strengthen participatory decision-making. In several cases, leaders discovered what their managers did not know, suggesting that training could help.

\section{Combining Dimensions}

The three model dimensions can be juxtaposed in a single computer-enabled, dynamic graphic, or used in pairs to illuminate issues. Figure 7, which focusses on two of the three dimensions of our museum, shows four quadrant categories: one that is positive on both axes, one that is negative on both, and two that are a mixture of positive and negative. By placing the sample programs within a two-dimensional mission / merit graph, we see that Space Rentals falls into the most negative quadrant, calling for urgent or dramatic action; that Core Collections shows up in the combined positive / negative one, focussing attention on quality issues; and that Special Exhibitions, which squeezes into the most positive, may need nudging or tweaking, but nothing urgent or dramatic. 


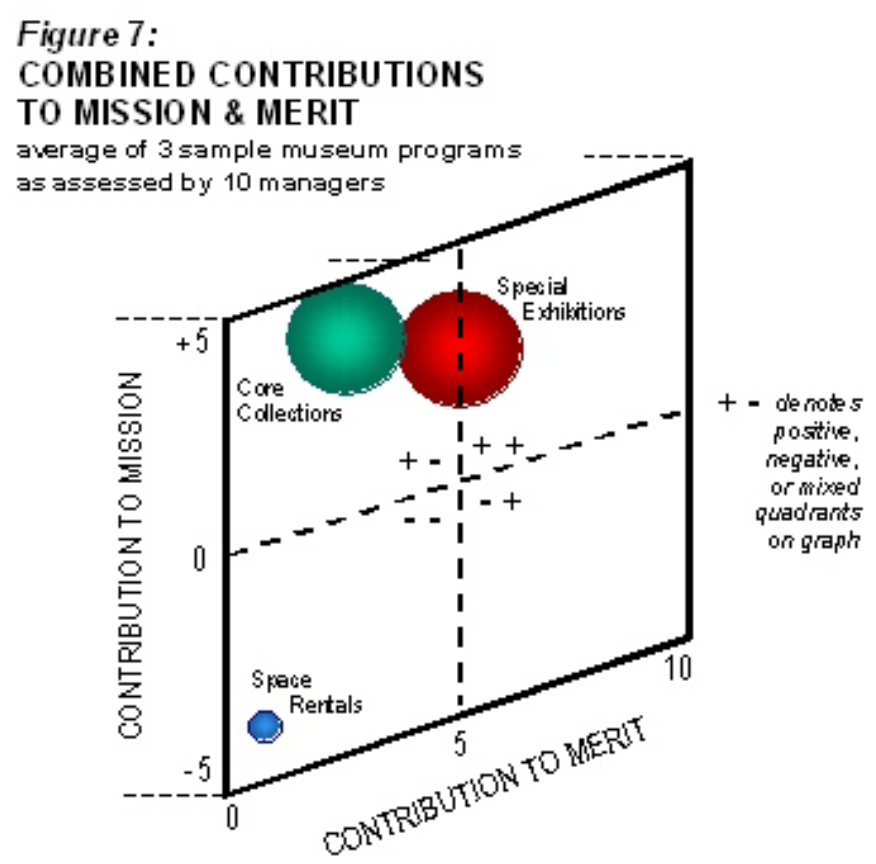

Other combinations produce other views. In three dimensions, the organization can get a full overview of how its managers, on average, place programs on three fundamental measures of effectiveness. Although it is difficult in print to show how programs are positioned dynamically in three dimensions, some implications of their overall placements can be imagined. First, Special Exhibitions shows up in the top right quadrant in every case - though sometimes only squeaking in. It suggests that further improvements can be made to this program with minimum interventions in cost containment, revenue enhancement, and quality stabilization. Second, Space Rentals provides surplus revenues to subsidize other programs, but half a million in net revenue against a million dollar cost may not be enough for a museum to keep it running when the program is badly performed and seriously detracts from mission. Eventually, if not already, it may be doing more damage than its relatively small surplus justifies. Certainly, it needs change. Third, Core Collections may be at the heart of a museum's mission, but the program has become enormously expensive and not one of whose performance the museum can be proud. It is possible that the poor performance is an outcome of inadequate financial support, but as easily it could be that agencies do not see this museum's care of collections as worthy of funding.

A view of the museum's full program portfolio (see Figure 1) now stimulates a search for areas where strategic or tactical change is needed. Not everything needs to be worked on at the same time, but the model makes visible which are most urgent and to which of the three important axes such change should be focussed. The centre of gravity (star) shows that the organization as a whole may be positively contributing to mission, but its financial position shows a current deficit which, if not turned around, may force draconian action in future. The mediocre performance of several programs requires equally rapid turnaround before they begin to erode not only mission but the organization's capacity to attract funding through grants and earned revenue.

Management can also use the model to play what-ifs: to visualize how much change is required in which programs to bring the centre to a more positive place. Over time, managers can review past actions to see how the centre of gravity has responded to specific interventions. It can also learn whether positive or negative movements on one axis affect movements on other axes. 


\section{From Institutional to Individual Input}

The figures above have illustrated average ratings of participants. Variability among managers is not yet visible. Because the model gathers all its input one person at a time, it can also show these individuals' best guesses and their highs and lows. If the organizational culture is safe enough and managers mature enough (although the model need not expose identities), such unveiling can tell individual managers and the organization as a whole even more. To use as an illustration two different managers' assessment of their museum's three sample programs on all three axes of the model, we see Figure 8.

\section{Figure 8:}

\section{TWO MANAGERS' ASSESSMENT OF PROGRAM CONTRIBUTION ON ALL THREE DIMENSIONS}

1st Manager

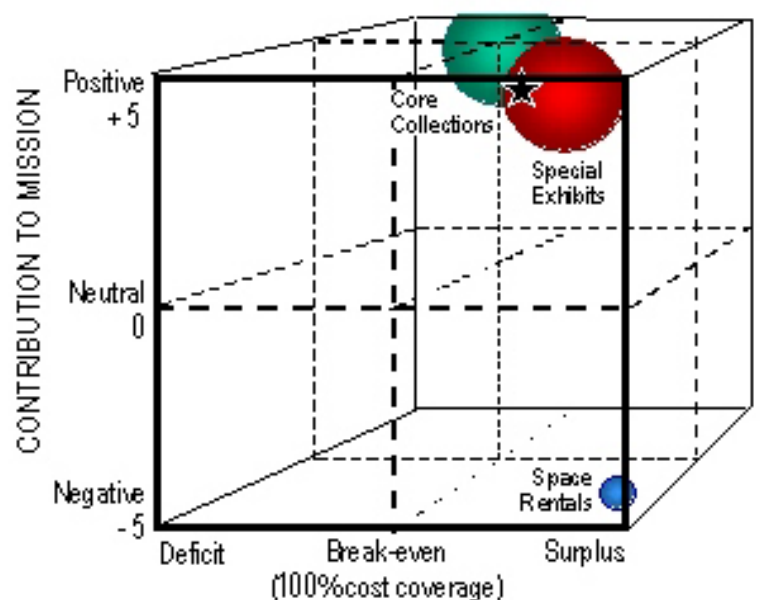

2n' Manager

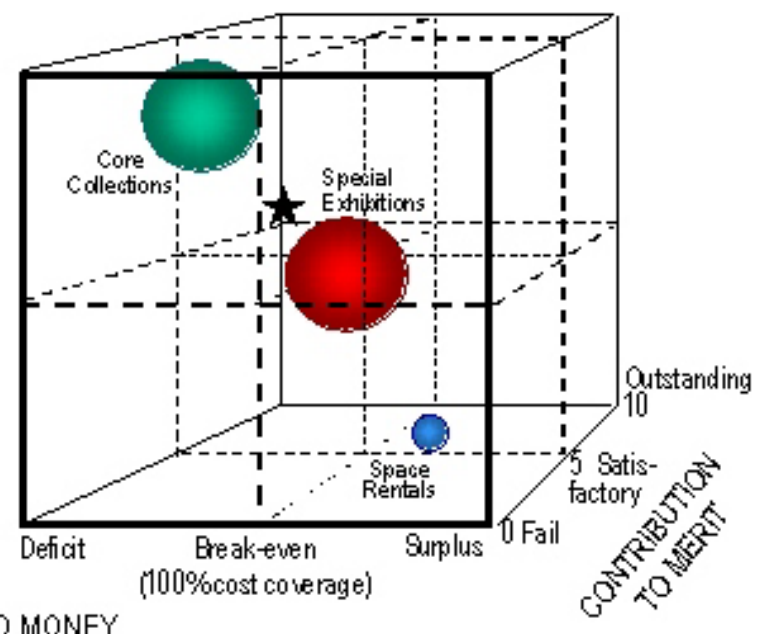

CONTRIBUTION TO MONEY

represents inolividual managers' personal "centres of gravity" or thee sample program 5

The first manager is the one who in our preceding anecdote stated that the museum's main Special Exhibition this year contributed perfectly to its mission because it had been done jointly with one of the originating communities in the region. His estimation of 'actual' for this program's mission contribution is a very high +4 . He gives a perfect rating for Core Collections, but puts Space Rentals at the far extreme of negative contribution to mission. On the money axis, he places the two large programs close to the break-even line - Collections a little under, Exhibitions a little over. He believes that Space Rentals is bringing in twice its cost, so puts it far into surplus. On the performance axis, he assesses the merit of each program to mirror his rating of its contribution to mission: perfect or very high for Collections and Exhibitions, and a fail for Space Rentals.

Four interpretations of this manager's assessments are possible: first, he may reflect the more 'traditional' museum professional view that values core programs and involvement with cultural communities over commercial activities; second, he has incomplete knowledge of program costs and revenues; third, he brings a less discriminating eye to program performance, perhaps assuming that if a program contributes to mission, it must be well done, and vice versa; and fourth, given the very high placement of his centre of gravity, he may see what the museum does as inherently good. 
This second manager is the one who said that because this year's main exhibition did not attract many visitors from the museum's region, it did not greatly advance mission - although she acknowledges that it did not detract from mission. She puts Special Exhibitions at +1 , or just above the neutral mission line. She agrees that Collections Care is what a museum is about, so places that high on mission advancement, but does not relegate Space Rentals to the mission and performance basement. Her assessment of program performance does not mirror its contribution to mission.

Four interpretations are also possible here: first, this manager brings a less traditional, perhaps more 'business-like' view to museum mission; second, she has better knowledge of what programs cost and attract in income; third, she does not automatically link program performance to mission; and fourth, given the less positive placement of her centre of gravity, she may be more critical about what the museum does.

Seeing how individuals deviate from the overall institutional average can contribute further to managerial learning through collective discussions about what the institution is actually doing. It can encourage managers to be more aware of what programs really cost and what they bring in, and to disentangle the evaluation of program performance from its contribution to mission. These exposures can encourage reviews of the mission statement to ensure it is clear to everyone and that incorrect assumptions and misleading interpretations do not create the kind of contradictions that occurred over the question, Whom does the museum serve: communities or visitors? Such questions are not easy for any management to answer, but the purpose of the model is not so much to answer questions as to pose or illuminate them. Good questions can be worth more than bad answers.

\section{Lessons from the Field}

We learned many lessons from testing our model with managers of nonprofit organizations. The following were notable:

\section{Define Programs Properly}

2 Get Acceptance

3 Fit the Organization
Programs need to be distinct in important ways to justify separate treatment and evaluation. In the model, six to ten programs of significance work best.

Visual aids can be powerful, but not everyone interprets models images intuitively. Disappointment or rejection are potential reactions. Patience and training help.

The model works best if in open organizational cultures and in nonprofits with adequate program complexity though breakdowns of single programs are possible.

4 Assure Confidentiality Participant confidentiality is important. Selecting the right person for information management is critical - at least at the start. Later, managers begin to self-reveal.

5 Separate Opinion from Fact

Dependability of input needs more than majority opinion. Accurate figures, rigorous analyses, systematic research, and experience still have a place in management.

Although the model can accommodate other dimensions, the three here provide sufficient complexity. Familiar, off-the-shelf software eases the process. 
$7 \quad$ Make it Timely

8 Invite Broader Input

9 Test Future What-Ifs

10 Require Performance Evaluation

11 Consider Summary Measures

12 Learn Safely and Enjoyably

13 Expose Systemic Issues

14 Improve Mission Statements
Using the model is best in normal strategic planning and annual budgeting cycles so perhaps twice a year. At the beginning, more frequent use is helpful for learning.

Computer capacity enables input from individuals beyond the management cadre and offers the nonprofit a natural extension toward more robust decision-making.

Testing of proposed new directions and changed priorities provides a potential new tool to better-considered decisions as well as buy-in to change.

The merit axis invites input of often-resisted expertise. It supports the nonprofit's demonstration of accountability to boards, governments, and other publics.

The centre of gravity is a gross measure. Though optional, it provides a quick fix on where the nonprofit as a whole stands. Its comparative value comes over time.

Expressing opinions as numbers and showing them as dynamic graphics evokes less personalized or historic assumptions than learning and enjoyment.

By constraining input, the model skews accounting traditions but also illuminates historic or systemic issues involving inclusions, exclusions, balances, and impacts.

By assessing programs against mission, not only are programs scrutinized, but so are mission statements and their varying interpretation by managers

\section{Summary}

In reflecting back on what our research might tell us and what we actually learned in the process, we were not only confirming the usefulness of three components of strategic decisionmaking - mission, money, and merit - nor simply testing how nonprofits would enter data into our three-dimensional decision-making model. It turned out that we were also developing a rich discussion and learning tool, as well as verifying that organization-wide decisions cannot be well made without first exposing managerial assumptions, conducting more rigorous measurements, and fixing missing or fuzzy mission statements, inadequate financial systems, and overly subjective or nonexistent performance evaluations. By illuminating what may be missing, models such as this one can help nonprofit leaders make strategic choices that achieve their mission, balance their budgets, and deliver high quality services. 


\section{References}

Adizes, I. "Introduction and Overview" to "Administering for the Arts," ed. Ichak Adizes, special edition of California Management Review, Winter 1972, pp. 98-102.

Anthony, R. N., and D. W. Young. Management Control in Nonprofit Organizations. Homewood, Ill.: R. D. Irwin, $6^{\text {th }}$ edition, 1998.

Chelimsky, E., and W. R. Shadish. (eds.). Evaluation for the 21t Century: A Handbook. Thousand Oaks, London, New Delhi: Sage Publications, 1997.

Drucker, P. F. "What Business Can Learn from Nonprofits," Harvard Business Review, 67 (4), 1989, pp. 88-93.

Jackson, P. M. “Editorial: Performance Measurement.” Public Money and Management, 15 (4), 1995, p. 3.

Kaplan, R. S. “Strategic Performance Measurement and Management in Nonprofit Organizations," Nonprofit Management \& Leadership, Spring 2001, pp. 353-370.

Kaplan, R. S., and D. P. Norton. The Balanced Scorecard : Translating Strategy Into Action. Boston, Mass.: Harvard Business School Press, 1996.

Krug, K. "Profit or Prostitution: Portfolio Analysis for Museum Marketing," MPR News, International Council of Museums Bulletin, 2 (2), 1992, pp. 13-19.

Lovelock, C. H., and Weinberg, C. B. Public and Nonprofit Marketing, New York: John Wiley \& Sons, 1980. 